\title{
An integrative marketing channel performance measurement framework
}

Received (in revised form): 3rd October, 2006

\section{Michael J. Valos}

is a senior lecturer in Marketing at Deakin University, Melbourne. He has a PhD in strategy implementation. His research interests include CRM and the role of marketing research in strategic decision making.

\section{Andrea Vocino}

is Associate Lecturer in Marketing at Deakin University and PhD candidate in the Department of Marketing, Monash University, Melbourne, Australia. His thesis is on the relationships between store names and product brand names as brand signals.

Keywords strategy implementation, marketing channels, strategic control, performance measurement, marketing metrics

Abstract This paper proposes a number of channel performance measurement research propositions. The paper reviews the strategy implementation, strategic control, marketing metrics, marketing channels and performance measurement literature to develop a conceptual model and research propositions. Current channel performance measurement guidelines are too generic for marketing managers and too reliant on financial measures. The introduction of contextual variables such as strategy, culture and manager's personality may provide measures more useful for an individual company's context and requirements. The alignment of channel measures with business strategy should result in more effective and efficient use of channel resources.

Journal of Database Marketing \& Customer Strategy Management (2006) 14, 17-28. doi:10.1057/palgrave.dbm.3250037

Michael J. Valos Faculty of Business and Law Bowater School of Management \& Marketing Deakin University, 221 Burwood Highway Burwood Vic. 3125 Australia

Tel: +613924 46168 Fax: +61392517083 E-mail: michael.valos@ deakin.edu.au

\section{INTRODUCTION}

Recent research into strategy implementation is damning in its findings. 'The reality is that traditional (marketing) implementation approaches have failed'. ${ }^{1,2}$ Similarly in the October 1999 issue of the Journal of Marketing, Noble and Mokwa ${ }^{3,4}$ wrote, '[Marketing] Implementation [...] is a critical link between formulation of marketing strategies and the achievement of superior organizational performance [...]. Yet, the nature of implementation and reasons for success or failure are understood poorly'.

According to Yeniyurt ${ }^{5}$, the marketing field is now giving high priority to developing marketing metrics. The role of marketing channels is to implement marketing strategy. The difficulty of channel strategy is compounded by the emergence of e-channels and the need to integrate e-channels into traditional or 'bricks and mortar' channels. ${ }^{6}$ Ambler et al. ${ }^{7}$ contend that metrics usage is substantially moderated by (a company's) size and sector. The authors suggest that 'larger firms use more metrics and the needs of retail, for example, are different from those in the consumer goods sector'. ${ }^{8}$

A fundamental proposition in marketing strategy is that distribution channels must 
be aligned with customers and competitive advantage. Unfortunately, channel performance measurement literature has provided ambiguous guidance to marketing managers. This paper addresses the problem by putting forward a conceptual model that uses strategy as the primary determinant of the characteristics of the performance measurement system.

Measurement plays a crucial role in strategy implementation according to Kaplan and Norton. ${ }^{9,10}$ Neely et al. ${ }^{11}$ conducted a review of the performance measurement literature. They observed that while many measurement frameworks have been developed and many others have offered criteria for the measurement system design, a generally pertinent systematic approach to performance measurement has not been built. In this respect, research in distribution channels has highlighted a 'channel performance metric paradox.' Because different systems and different channels necessitate particular measurement structure characteristics, it is impossible for a business organisation to maximise concurrently, all channel performance measures.

The literature argues, however, that the extent to which each determinant of performance impacts firm performance is a function of the performance metrics (see, eg Eccles ${ }^{12}$; Neely ${ }^{13}$; Simons ${ }^{14}$ ). Further, Lebas and Euske ${ }^{15}$ define performance as 'the sum of all processes that will lead managers to taking appropriate actions in the present that will create a performing organisation in the future' or in other words, 'doing today what will lead to measured value outcomes tomorrow' ${ }^{16}$

This paper is conceptual in nature and while adopting Miles and Snow strategy types' framework, it offers a model that endeavours to reconcile the 'channel performance metric paradox'. In so doing, we show that in order to achieve marketing success, it is important to understand the relationship between channel performance measures and strategy deployment success. Our research seeks to identify that strategy is the key determinant of channel metric characteristics.

This paper is organised in the following way. First, a review of the performance measurement, marketing channels and strategy implementation literature is undertaken. Next, channel performance measurements are integrated with Miles and Snow's strategy implementation framework. Following that a research model that is specific to channels is developed with research propositions. Finally, guidance is provided to marketing managers in the use of the model in framing a system of marketing channel performance measurement.

The paper contributes to marketing practice by clarifying the key channel performance measures in an organisational context. It also identifies which performance measures should be emphasised to avoid the channel performance metric paradox. This paradox occurs where undesirable performance trade-offs occur when the improvement of one performance measure reduces the performance of another measure.

\section{INTEGRATING MARKETING CHANNELS, PERFORMANCE MEASUREMENT AND STRATEGY IMPLEMENTATION LITERATURE}

\section{Channel performance literature}

'The strategic nature of distribution channel has been well-established in the extant literature. ${ }^{17,18}$ A business firm can be seen as a portfolio of marketing channels having different function, structure and behaviour, with the objective of adding value to the process of making products and services available to business and household consumers.

Prior research (see, eg Jeuland and Shugan ${ }^{19}$; Larson and $\operatorname{Lusch}^{20}$; Lewis and Lambert ${ }^{21}$ ) has shown correlations among 
channel performance measures being either orthogonal or negative.

The Porterian view of strategy developed in the 1980s influenced, to some extent, channel research published in the early 1990s, which suggested that organisations, in order to be successful, were required to match suitable channel performance measures with their strategy. ${ }^{20-23}$ In later research, Stock et al. ${ }^{24}$ have instead adopted a more Mintzbergian view, whereby, in the context of distribution channels, the link between strategy and structure seemed to be a more prominent explanation of business success.

Channel performance can be measured in many fashions. The accounting literature, for instance, has adopted measures like 'firm survival' in the longer term and return of investments and return of assets in the shorter term. Financial performance indicators have been, however, criticised of being myopic. ${ }^{9,10,12,25,26}$ In public sector operations (eg public broadcasting, telephone companies and the post office), the current endeavour is to measure performance by assessing the overall quality of service delivered to specific stakeholders. When these stakeholders are of societal importance, then the societal indicators typically focus on changes in the human condition and therefore are much less financially based. ${ }^{27}$ Last but not least, channel performance can be measured as a function of efficiency. It should focus on how well the firm minimises costs associated with performing necessary channel functions such as transferring goods from the manufacturer to the end consumer disregarding the profits made at any point along the line.

Clearly, there must be a reason behind the diversity of channel performance measures. Each of the preceding authors suggests their channel measures lead to organisational success through effective channel management.
Evidently, each individual measure of performance has limitations and is incomplete. Rather, a combination of the available measures is necessary to appropriately judge true channel performance. Further, different combinations will be appropriate in different situations. The difficulty of performance measurement is to determine the underlying structure that defines the combination of measures most suited to a particular set of circumstances. In order to achieve this, a framework of channel performance metric guidelines is required. This research intends to identify that strategy is the key determinant of channel metric characteristics.

In order to achieve marketing success, it is important to understand the relationship between channel performance measures and strategy implementation success. It is also important to know whether, regardless of marketing strategy, the same channel performance measures should be used.

The key question in terms of ensuring that channel strategy supports marketing performance is: How do we know our channel strategy is performing? We only understand performance according to the channel performance measures selected. Therefore, in order to understand whether the channel is performing or not, we need to ensure that the channel measures are appropriate for each marketing strategy.

In response to this research gap, this paper investigates whether channel performance measures should differ according to marketing strategy. We pose the question 'Is marketing strategy a bigger determinant on channel performance measures than other variables such as: stage of product lifecycle, market share, organisational size, business unit size, industry profitability, industry growth, marketing manager characteristics, external environment or competitors?' 


\section{Performance measurement literature}

Traditional performance measurement systems were both outcome focused and financially focused and were neither multidimensional nor strategic. ${ }^{5}$ In the 1990s, performance measurement systems became broader and included measures of innovation and customer satisfaction. Yeniyurt $^{28}$ reports that UK companies '[...] still consider internal financial measures more important than external market measures.' The literature suggests that accurate measurement of marketing performance allows marketing managers to objectively and regularly assess the quality of their decisions ${ }^{25}$ and is central to the learning organisations' success. ${ }^{29,30}$ Further, the role of marketing measures is also to help implement marketing strategy. 'The Marketing Science Institute has raised marketing metrics to become its leading capital research project [and ...] the increasing interest in justifying marketing investment is not limited to financial metrics. ${ }^{8}$ Hence, marketing performance and channel performance can also be seen as a function of the quality of marketing metrics.

The fundamental rationale of any business measurement system is to cater for feedback, relative to one organisation's goals, that intends to advance the organisation's probabilities of accomplishing these goals in an effective and efficient manner. In that, performance measurement systems support managers in monitoring the deployment of business strategy by evaluating actual outcomes related to strategic goals and objectives. $^{14}$

Schmitz and Platts ${ }^{31}$ consider performance measurement has the following functions: strategy formulation and clarification, management information, vertical communication, horizontal communication, decision-making and prioritising, coordination and alignment, motivation and learning. These are all functions that have the potential to assist marketing channels implement strategy and deliver competitive advantage. Lubieniecki and Desrocher ${ }^{32}$ propose the following three benefits for a comprehensive and consistent performance measurement system: superior resource allocation, more effective activity prioritisation and competitive benchmarking.

\section{Strategy implementation literature}

One way of examining strategy

implementation differences is through the use of a strategic typology. Strategic typologies assume that an organisation or business unit with a given marketing strategy has specific guidelines for human resource and organisational structure practices. The typology has an underlying assumption of adaptiveness. Miles and Snow $^{33}$ put forward the three successful generic strategies of Prospector, Defender and Analyser as the means by which an organisation could successfully cope with the industry forces and degree of environmental uncertainty.

According to Miles and Snow, the Prospector strategy achieves competitive advantage through being the first into new markets with new products. It is innovative and adapts to new technology well. In contrast, the Defender achieves competitive advantage by being more efficient. This means it does not have to be first into new markets with new products. Defenders tend to have less product innovation than Prospectors who aim to compete through innovative product or service features. The third of the generic strategies is the Analyser strategy. This strategy combines elements of the Prospector and Defender. The Analyser may be aggressive in some markets and defensive in others. It could be seen as an opportunistic strategy. This is because it attempts to seize the best opportunities. It does this even if this results in internal tensions or inconsistencies.

As a result, the Prospector and Defender types have totally contrasting human 
resource, organisational structure and most importantly for this paper, performance control guidelines.

\section{Miles and Snow and channel performance measurement}

As far as channel performance is concerned both the Miles and Snow and Porter strategy typologies have specific performance control guidelines, which vary according to strategy type. Unfortunately, the Miles and Snow performance measurement guidelines have received only minor empirical attention and with the emergence of e-channels, ${ }^{6}$ further research is required.

Prospectors would have more adaptive, flexible, externally focused and organic channel performance measures than Defenders. Miles and Snow say the performance control methods of the Prospector are loose and organic with control being decentralised throughout the organisation. Conversely, the Defender with a more predictable future and more detailed plans can develop tighter more comprehensive controls. This is because the Defender has more predictable processes and outcomes. Analysers would have a mix of tight and loose (ie organic and mechanistic) channel measures due to their mixture of Prospecting and Defending activities.

Strategy typologies suggest each strategy must recognise that they have different performance control requirements in terms of the following performance metric dimensions: financial vs non-financial, subjective vs objective and qualitative vs quantitative, etc. Strategy typologies suggest each strategy type requires internally consistent channel measures. For example, tight or mechanistic performance measures are inappropriate for Prospectors as they would conflict with other implementation tools such as reward systems, empowerment, participative decision-making and culture. In the same way, loose or organic channel performance measures would conflict with internal culture and organisational characteristics of Defenders.

Where no literature is available regarding strategy implementation issues of the Miles and Snow strategic types, an assumption has been made that literature regarding the Porter strategy types will provide a theoretical basis for the research model. This is appropriate because the typologies are similar and yet not identical. For example, Porters Differentiators often compete with new products and innovation in the manner of the Miles and Snow Prospectors, while many Miles and Snow Defenders compete on low cost and low price in the manner of the Porter Cost Leaders. Both typologies are based on a mechanistic vs organic underlying dimension.

\section{Non-financial vs financial channel performance measurement}

Traditional performance measurement systems were financially focused and were neither multidimensional nor strategic. ${ }^{5}$ The Miles and Snow strategic-type literature provides a multidimensional characteristic to performance measures.

Collins et al. ${ }^{34,35}$ had surprising findings when studying the strategy metric relationship. The data '[...] contradict[ed] some of the contingency theorists ... who felt that qualitative, non-financial controls were more appropriate for Prospector-like organizations since formal procedures might stifle innovativeness. Unexpectedly, the Defender, Analyzer and Reactor strategy types were not related to budgetary usefulness.' Simons expected that tight budget goals and output goals would be positively related to Defender performance. Simons ${ }^{36,37}$ says 'the lack of significance for Defenders of factors relating to cost control is surprising.'

In terms of the Porter strategies, Lassar and $\mathrm{Kerr}^{38,39}$ found that 'Cost Leaders maintained an arm's length control relationship based on financial outcomes 
[...].' With Cost Leaders and Defenders both having a cost and internal efficiency focus, it is likely that financial measures would be emphasised. Conversely for Differentiators and Prospectors, the unpredictable nature of their more innovative strategies makes the relationship between finance and strategy more tenuous and consequently less meaningful.

\section{Frequent vs infrequent channel performance measurement}

Surprisingly, Simons ${ }^{40}$ found the approach taken to control by successful large Prospectors involved frequent performance reporting. This contrasts with Porter who said Cost Leaders required 'frequent performance reports. ${ }^{41,42}$ This suggests that Defenders similarly would require frequent performance reports. Defenders would be expected to be similar to Cost Leaders as they operate in relatively certain environments with existing customers and undertake little product innovation. As a result, the measures they use could be frequent yet still be meaningful. Issues faced by Defenders lend themselves to being quantified. This contrasts with high-risk innovative Prospector strategies that may take time to assess. In terms of the Porter types, White ${ }^{43,44}$ found no link between frequency of performance reviews and either return on investment or sales growth for Differentiators or the Porter Combination strategy. For the Cost Leader, he found a relationship between frequency of performance reviews and return on investment but no relationship between frequency of performance reviews and sales growth.

\section{Short-term vs long-term channel performance measurement}

As discussed above, Prospector strategies may take longer to eventuate while Defenders have a more 'here and now' focus. In terms of the product lifecycle, the Defenders are closer to 'Harvest' than either
'Introduction' or 'Growth' stages. As discussed above, Defender goals lend themselves to being quantified compared to the high-risk innovative Prospector strategies that may take time to assess.

\section{Behavioural vs output channel performance measurement}

Traditional performance measurement systems were outcome focused and neither multidimensional nor strategic. ${ }^{5}$ Simons ${ }^{40}$ surprisingly found the control methods of successful Prospectors included careful output monitoring. This behaviour was expected to be associated with Defenders. Research on the Porter types by Govindarajan and Fisher ${ }^{45,46}$ found ' $[\ldots]$ cost leadership and differentiation strategies need to be matched with output and behaviour controls [...].' They found that Differentiators were more likely to be effective when using behavioural measures comprising subjective non-financial data. Conversely, Lassar and Kerr ${ }^{38,39}$ did not support Porter. They found that 'Cost Leaders maintained an arm's length control relationship ... with few behavioural (control measure) stipulations.'

\section{Subjective vs objective channel performance measurement}

Paswan $^{47}$ provides a range of organisational characteristics which affect channel management decisions. One of these was management's perception of their firms' orientation, organisational culture, internal emphasis on financial vs marketing relented achievements. In this way, subjective measures of managers may be more important than objective measures of performance.

Porter said Cost Leaders would be more successful when using objective performance measures. Govindarajan and Fisher ${ }^{48}$ found that Differentiators were more likely to be effective when using subjective nonfinancial controls. This is due to the innovation inherent in this strategy. This 
suggests Prospectors require subjective measures.

\section{Product quality vs cost channel performance measurement}

Based on the degree of product innovation inherent in Prospector strategies, it is likely that they would compete with higher quality products and be first to market with new generation products. Conversely, Defenders would depend more on efficiency and cost reduction to compete and rely more on older generation products. As a result, Defenders would place greater emphasis on cost control measures in supporting marketing strategy.

\section{Qualitative vs quantitative channel performance measurement}

As discussed above, Collins et al. ${ }^{34,35}$ had surprising findings regarding strategy implementation. The data '[...] contradict(ed) some of the contingency theorists $[\ldots]$ who felt that qualitative, non-financial controls were more appropriate for Prospector-like organizations since formal procedures might stifle innovativeness.' White ${ }^{43,44}$ provided what could be termed mixed findings concerning the theorised relationships between Porters strategies and performance measures. This finding supports the 'channel performance metrics paradox' referred to earlier. White ${ }^{49}$ found both Differentiators and Cost Leaders were similar in terms of using objective quantitative performance measures.

\section{External vs internal channel performance measurement}

As Prospectors target new markets, it appears appropriate they emphasise external measures. Conversely, Defenders would rely more on existing markets and need to monitor internal efficiency while they compete with older generation products. It is interesting to note that Yeniyurt ${ }^{28}$ reports that UK companies ' $[. .$.$] still consider$ internal financial measures more important than external market measures.'

\section{Strategic vs tactical channel performance measurement}

Lubieniecki and Desrocher ${ }^{32}$ argue performance measures must be aligned with corporate strategy. Fiegener ${ }^{50}$ found that the Porter Combination strategy which combines Differentiation and Cost leadership strategies needed tight strategic control but loose implementation (cf. low level) control. In other words, the optimum control system required two different approaches operating at different hierarchal levels. Further, he found that Combination strategies and Cost Leader strategies needed loose and tight controls at different hierarchical levels.

A similar logic could be used for developing research propositions for the Miles and Snow strategy types. Defenders working in the realm of low-risk strategy have less need for strategic control measures. But Prospectors require strategic control rather than tactical control due to their high-risk innovative strategies.

\section{CHANNEL PERFORMANCE MEASUREMENT RESEARCH MODEL}

\section{Model assumptions}

The assumption underlying the model is that marketing strategy is the key determinant of appropriate channel measures. The model suggests marketing strategy is a more important influence on channel measures than variables such as marketing manager characteristics, stage of product lifecycle, market share, organisational or strategic business unit size, industry profitability and growth, environment or competitors. Table 1 shows the proposed relationships between channel measures for each Miles and Snow strategy type.

Other determinants that should be included in testing the model are derived 
Table 1: Research propositions - channel performance metric guidelines for Miles and Snow strategy types

\begin{tabular}{ll}
\hline Prospector & Defender \\
\hline Subjective & Objective \\
Non-financial & Financial \\
Frequent & Infrequent \\
Behavioural & Output \\
Product quality & Cost \\
Qualitative & Quantitative \\
External & Internal \\
Strategic & Tactical \\
Long-term & Short-term \\
\hline
\end{tabular}

from the performance measurement literature. Neely et al. ${ }^{11}$ argue that performance management must match the organisational culture. It is possible that organisational culture is as important as strategy in influencing the most appropriate channel performance measures. Like strategy, we propose that a measure of culture must also be included in the testing of our research proposition. Franco and Bourne $e^{51}$ discuss a number of organisational variables they see as being related to successful performance measurement systems. These variables may also be an influence on the optimal channel performance measurement framework for an organisation. These variables include culture, reward and compensation systems, leadership and finally, degree of external market competition.

Paswan ${ }^{47}$ provides a range of organisational characteristics which affect channel management decisions. It is possible that these characteristics also influence an appropriate framework of channel performance measures. These characteristics include management perception of firms orientation, organisational culture, internal emphasis on financial vs marketing relented achievements. They should also be tested in conjunction with a research proposition that strategy is the primary influence of appropriate channel measures.

The Prospector strategy with its emphasis on innovation and premium product quality needs to closely monitor customers. This means it requires channel performance measures that are characterised by external focus, adaptiveness and flexibility. In other words, 'organic' measures rather than 'mechanistic' ones are more suitable for Prospectors. The Defender with its emphasis on cost control and process efficiency requires channel performance measures characterised by rigidity, internal focus and standardisation.

The key assumption of the research model is that Miles and Snow suggest that managers and employees of Prospectors are faced with greater task variety and have less existing policies and procedures for dealing with issues. This is due to the greater uncertainty in the Prospector strategy, which is innovative and less predictable. Conversely, Miles and Snow ${ }^{33}$ say that employees of Cost Leaders have structured responsibilities, frequent reporting and a culture which focuses on detail.

The model proposes that successful marketing implementation and marketing performance occurs when strategy is aligned to channel performance measures. The dimensions of these measures include measurement frequency, financial vs nonfinancial, qualitative vs quantitative, shortterm vs long term, strategic vs tactical, behavioural vs objective, etc. The model proposes that channel implementation will support marketing implementation when the characteristics of the preceding channel measures are given emphasis by the marketing manager according to marketing strategy.

The measures required for the Analyser strategy are unclear compared to Prospectors and Defenders as the Analyser relies on being aggressive in some markets and passive or defensive in other markets. In other words, it requires a mixture of channel performance measures with some having Prospector traits and others having Defender traits. For the sake of clarity, it is excluded from Table 1. Further support for this view of the Analyser channel measures is provided by the Fiegener. ${ }^{50}$ study which 
studied the Porter Combination strategy. This strategy type has both Differentiation and Cost Leader characteristics and was found to have a mixture of Differentiator and Cost Leadership performance control characteristics.

The benefit of the Table 1 model is that it extends knowledge of relationships between Miles and Snow strategy types and a comprehensive range of channel performance measures. It will test the 'channel performance metric paradox' mentioned in the literature. ${ }^{19-21}$ The findings will test the possibility that performance of all channel measures can be maximised simultaneously or whether tradeoffs between performances measures occur.

\section{Research question}

To what degree is marketing performance determined by the alignment of channel performance measures with marketing strategy?

\section{Equafinality - a competing explanation to strategy type and contingency theory as determinants of a channel performance model}

The assumption underlying this model is that contingency theory and its related theory of strategy types holds.

An alternate school of thought which may explain the 'channel performance metric paradox' is the equafinality view. ${ }^{52-54}$ The equafinality school of thought proposes that organisations are so different from each other that no two organisations will use the same approach to strategy implementation. In contrast to the assumptions inherent within this model, the Equafinality theory proposes that there are no generic solutions to the 'channel performance metric paradox' referred to in the literature. ${ }^{19-21}$ Further, Equafinality suggests that no two organisations will have the same set of performance measures.

In other words, Equafinality implies each organisation uses a battery or suite of seemingly inconsistent and conflicting channel measures, which nonetheless allow it to achieve marketing performance. It proposes that many possible different combinations of channel performance characteristics exist, each allowing successful implementation for any of the Miles and Snow strategy types. Equafinality would explain the lack of strong relationships found in previous research that sought relationships between performance measures and strategy types. The context of each business unit may be a bigger influence on channel performance measures than marketing strategy. In other words, there may be other organisational variables or characteristics that have greater influence on appropriate channel performance measures than strategy. These other influences include stage of product lifecycle, market share, organisational size, business unit size, industry profitability, industry growth, marketing manager characteristics, external environment and competitors.

\section{Implications for researchers}

Schmitz and Platts ${ }^{31}$ in a review of performance measurement literature report that there is 'an extensive amount of normative literature ${ }^{55}$ but a lack of empirical research. Further, 'despite its (Balanced Scorecard) popularity among academics there is a lack of empirical research related to the (Balanced Scorecard) method. ${ }^{28}$ This framework and the research propositions provide a basis to test a multidimensional model which compares the major determinants of measure appropriateness (cf. strategy, culture, reward systems).

This research incorporates strategy type theory which in turn utilises contingency theory as a means of linking organisational theory, strategy implementation and performance measurement. The model and research propositions provide a test of the strength of contingency theory in explaining strategy implementation, and in 
particular channel performance measurement. The results may, however, support the alternative concept of equafinality that represents:

(a) A quandary for traditional contingency theory research according to Gresov and Drazin ${ }^{52,53}$ equafinality means ' $[. .$. multiple design alternatives may exist for effectively implementing strategy.' Further ' $[\ldots]$ elements of control systems and elements of structure could be used as substitutes for one another to effectively implement any given strategy.'

(b) An explanation for the 'channel performance metric paradox' highlighted in the channel performance literature review.

\section{IMPLICATIONS FOR MARKETING MANAGERS}

According to Najmi et al., ${ }^{56}$ business believe that performance measurement frameworks should be multidimensional. Unfortunately, the early attempts at performance measurement frameworks were too financially oriented and did not provide strategic vision. Najmi et al. ${ }^{56}$ state that an ideal performance measurement system must include measures which are strategically relevant as well as measures which address both efficiency and effectiveness. Lubieniecki and Desrocher ${ }^{32}$ consider managers have too many performance measures, and a simplified set with fewer yet more important metrics would lead to superior performance. Neely et al. ${ }^{11}$ argue that performance management systems are hindered by too many low-level measures.

For marketing managers, the area of channel performance measurement is an area that represents a significant opportunity for business investment and management attention. The interdisciplinary conceptual model will provide guidance to marketing managers in developing contextually relevant channel measures. The model informs the marketing manager that marketing strategy should be the primary determinant of an organisation's channel measure framework. It guides the manager in a way that avoids the 'channel performance metric paradox', which results in sub-optimisation of the performance measurement portfolio. The model provides marketing managers with specific benefits such as:

1 Explicit measures to facilitate internal communication and aid coordination of the multiple stakeholders involved in channel implementation, for example, eCommerce area, sales operations, call centre, external partners, etc.

2 A strategically aligned framework for clearer logic behind actions. More appropriate channel performance measurement should result in less internal conflict or ambiguity between areas such as eCommerce, bricks and mortar channels, call centres and field sale force.

3 A performance measure portfolio that discriminates between efficiency and effectiveness performance measures in order to avoid suboptimal performance. Marketing managers need clarity in determining the difference between efficient vs effective performance measures.

4 A framework that will provide multichannel marketers guidance. For example, a call centre can reduce costs and improve profit by reducing service quality but this will reduce cross-selling effectiveness, which will reduce profits. In other words, improving one performance measure can adversely affect other performance measures where a comprehensive framework is not used.

5 A set of guidelines to ensure channel synergies are achieved in the targeting of high and low customer lifetime value segments. Matching channel costs and channel response to customer value. 
In other words, the integration between market segmentation strategy and channel strategy should be enhanced.

\section{References}

1 Dobni, B., Dobni, D. and Luffman, G. (2001)

'Behavioural approaches to marketing strategy implementation', Marketing Intelligence \& Planning, Vol. 19, No. 6, pp. 400-408.

2 Dobni, B., Dobni, D. and Luffman, G. (2001) op cit.

3 Noble, C. H. and Mokwa, M. P. (1999)

'Implementing marketing strategies: Developing and testing a managerial theory', Journal of Marketing, Vol. 63, No. 4, pp. 57-73.

4 Noble, C. H. and Mokwa, M. P. (1999) op cit.

5 Yeniyurt, S. (2003) 'A literature review and integrative performance measurement framework for multinational companies', Marketing Intelligence \& Planning, Vol. 21, No. 3, pp. 134-142.

6 Rowley, J. (2002) 'Synergy and strategy in e-business', Marketing Intelligence \& Planning, Vol. 20, No. 4/5, pp. 215-222.

7 Ambler, T., Kokkinaki, F. and Puntoni, S. (2002) 'Assessing market performance: The current state of metrics', Working Paper No. 01-903, London Business School Centre of Marketing, London.

8 Ambler, T., Kokkinaki, F. and Puntoni, S. (2002) op cit.

9 Kaplan, R. S. and Norton, D. P. (1996) 'Linking the balanced scorecard to strategy', California Management Review, Vol. 39, No. 1, pp. 53-79.

10 Kaplan, R. S. and Norton, D. P. (1996) 'Using the balanced scorecard as a strategic management system', Harvard Business Review, Vol. 74, No. 1, pp. $75-85$.

11 Neely, A. D., Gregory, M. and Platts, K. (2005) 'Performance measurement system design: A literature review and research agenda', International Journal of Operations \& Production Management, Vol. 25, No. 12, pp. 1228-1263.

12 Eccles, R. G. (1991) 'The performance measurement manifesto', Harvard Business Review, Vol. 69, No. 1, pp. 131-137.

13 Neely, A. D. (1998) 'Measuring business performance', The Economist Books, London.

14 Simons, R. (1999) 'Performance measurement and control systems for implementing strategy', Prentice Hall, Upper Saddle River, NJ.

15 Lebas, M. and Euske, K. (2002) 'Delineation of performance', in: Neely, A. (Ed.) ' Business performance measurement: Theory and practice', Cambridge University Press, Cambridge, UK, pp. 65-79.

16 Lebas, M. and Euske, K. (2002) op cit.

17 Paswan, A. K. (2003) 'Channel support activities and perceived goal orientation: An exploration in the Indian market', Asia Pacific Journal of Marketing and Logistics, Vol. 15, No. 4, pp. 19-41.

18 Paswan, A. K. (2003) op cit.
19 Jeuland, A. P. and Shugan, S. M. (1983) 'Managing channel profits', Marketing Science, Vol. 2, No. 3, pp. 239-272.

20 Larson, P. D. and Lusch, R. F. (1992) 'Functional integration in marketing channels: A determinant of product quality and total cost', Journal of Marketing Channels, Vol. 2, No. 1, pp. 1-28.

21 Lewis, M. C. and Lambert, D. M. (1991) 'A model of channel member performance, dependence, and satisfaction', Journal of Retailing, Vol. 67, No. 2, pp. 205-225.

22 Jaworski, B. J. and Kohli, A. K. (1991) 'Market orientation: Antecedents and consequences', Journal of Marketing, Vol. 57, No. 3, pp. 53-70.

23 Larson, P. D. (1991) 'Product quality, total costs and the integration of the utility-producing functionsunpublished $\mathrm{PhD}$ dissertation University of Oklahoma.

24 Stock, G. N., Greis, N. P. and Kasarda, J. D. (1998) 'Logistics, strategy and structure - A conceptual framework', International Journal of Operations \& Production Management, Vol. 18, No. 1-2, pp. 37-52.

25 Chakravarthy, B. S. (1986) 'Measuring strategic performance', Strategic Management Journal, Vol. 7, No. 5, pp. 437-458.

26 Kaplan, R. S. and Norton, D. P. (1992) 'The balanced scorecard - Measures that drive performance', Harvard Business Review, Vol. 70, No. 1, pp. 71-79.

27 Ogata, K. and Goodkey, R. (2002) 'Redefining government performance’, in: Neely, A. (Ed.) 'Business performance measurement: Theory and practice', Cambridge University Press, Cambridge, UK, pp. 259-278.

28 Yeniyurt, S. (2003) op cit.

29 Slater, S. F. and Narver, J. C. (1995) 'Market orientation and the learning organization', Journal of Marketing, Vol. 59, No. 3, pp. 63-74.

30 Sengè, P. M. (1990) 'The leader's new work. Building learning organizations', Sloan Management Review, Vol. 32 (Fall), pp. 7-24.

31 Schmitz, J. and Platts, K. W. (2004) 'Supplier logistics performance measurement: Indications from a study of the automotive industry', International Journal of Production Economics, Vol. 89, No. 2, pp. 231-243.

32 Lubieniecki, E. C. and Desrocher, N. J. (2003) 'The case for simple comparison: A simple performance scorecard for effectiveness and efficiency', Journal of Corporate Real Estate, Vol. 6, No. 1, pp. 39-52.

33 Miles, R. E. and Snow, C. C. (1978) 'Organisational strategy, structure, and process', McGraw-Hill, New York.

34 Collins, F., Holzmann, O. and Mendoza, R. (1997) 'Strategy, budgeting, and crisis in Latin America', Accounting, Organisations and Society, Vol. 22, No. 7, pp. 669-689.

35 Collins, F., Holzmann, O. and Mendoza, R. (1997) op cit.

36 Simons, R. (1987) 'Accounting control systems and business strategy: An empirical analysis', Accounting Organisations and Society, Vol. 12, No. 4, pp. 357-374.

37 Simons, R. (1987) op cit. 
38 Lassar, W. M. and Kerr, J. L. (1996) 'Strategy and control in supplier-distributor relationships: An agency perspective', Strategic Management Journal, Vol. 17, No. 8, pp. 613-632.

39 Lassar, W. M. and Kerr, J. L. (1996) op cit.

40 Simons, R. (1987) ibid.

41 Porter, M. E. (1980) 'Competitive strategy', Free Press, New York.

42 Porter, M. E. (1980) op cit.

43 White, R. E. (1986) 'Generic business strategies, organizational context and performance: An empirical investigation', Strategic Management Journal, Vol. 7, No. 3, pp. 217-231.

44 White, R. E. (1986) op cit.

45 Govindarajan, V. and Fisher, J. (1990) 'Strategy, control systems, and resource sharing: Effects on business-unit performance', Academy of Management Journal, Vol. 33, No. 2, pp. 259-285.

46 Govindarajan, V. and Fisher, J. (1990) op cit.

47 Paswan, A. K. (2003) ibid.

48 Govindarajan, V. and Fisher, J. (1990) ibid.

49 White, R. E. (1986) ibid.
50 Fiegener, M. K. (1994) 'Matching business-level strategic controls to strategy: Impact on control system effectiveness', Journal of Applied Business Research, Vol. 10, No. 1, pp. 25-34.

51 Franco, M. and Bourne, M. (2003) 'Factors that play a role in "managing through measures", Management Decision, Vol. 41, No. 8, pp. 698-710.

52 Gresov, C. and Drazin, R. (1997) 'Equifinality: Functional equivalence in organization design', Academy of Management Review, Vol. 22, No. 2, pp. 403-428.

53 Gresov, C. and Drazin, R. (1997) op cit.

54 Kumar, K. and Subramanian, R. (1997/1998) 'Porter's strategic types: Differences in internal processes and their impact on performance', Journal of Applied Business Research, Vol. 14, No. 1, pp. 107-124.

55 Schmitz, J. and Platts, K. W. (2004) op cit.

56 Najmi, M., Rigas, J. and Fan, I. -S. (2005) 'A framework to review performance measurement systems', Business Process Management Journal, Vol. 11, No. 2, pp. 109-122. 